\title{
First Derivative of Intraventricular Pressures in Complete Transposition of Great Vessels ${ }^{\star}$
}

\author{
PRAVIN SHAH $\dagger$ AND LANGFORD KIDD
}

From the Department of Cardiology and the Research Institute, Hospital for Sick Children, Toronto, Canada

The first derivative of intraventricular pressure (dp/dt) reflects the rate of development of tension in the myocardium and has been employed as an index of contractility. The peak $\mathrm{dp} / \mathrm{dt}$ of left ventricular (LV) pressure in the normal heart is higher than the right ventricular $(R V)$ peak dp/dt. It is not known whether this is related to the basic difference in the architecture of the ventricular muscle or to the disparity in wall thickness. Rushmer (1961) has demonstrated by cinefluorographic studies that the mechanism by which the two ventricles eject blood is different, and concludes that the architectural design of the right ventricle is ideally suited to the ejection of large volumes of blood with a minimal amount of myocardial shortening and is not conducive to the development of high intraventricular pressures; the left ventricle, on the other hand, was felt to be designed as a high-pressure pump. The essential architectural difference relates to the orientation of muscle fibres.

In order to test the validity of these teleological explanations for anatomical differences, it would be necessary to test some parameters of ventricular function under circumstances where the function of the ventricles is reversed. Nature has provided precisely this situation in patients with complete transposition of great vessels, where the anatomical right ventricle faces the high pressure/high resistance systemic circuit and the anatomical left ventricle faces a pulmonary circuit that has a variable resistance. It was decided to study the ventricular pressures and their first derivative in cases of complete transposition of the great vessels with normally related ventricles, as shown by angiocardiography.

Received January 13, 1966.

* This work was supported by grants from the Ontario Heart Foundation and the Department of National Health and Welfare, Ottawa, Canada.

† Present address: 12 Carmichel Road, Bombay 26, India.

\section{SUBJECTS AND METHODS}

Seven patients with complete transposition are included in the present study. Their ages at the time of study varied between 6 months and 13 years. A diagnostic cardiac catheterization was performed with a No. 5 or No. 6 Lehman catheter. Estimations of oxygen content in the aorta, the two atria and ventricles, and the systemic and pulmonary veins were made in all cases. The pulmonary artery could be entered in only one case. Flow ratios were calculated from systemic and pulmonary arteriovenous oxygen differences. The oxygen content of the sample in the left ventricle has been assumed to be a reasonable approximation of that in the pulmonary artery. Oxygen saturations and contents were measured with a Wood Cuvette Oximeter and Van Slyke manometric analysis.

The pressures were recorded by Statham pressure transducers $(\mathrm{P} 23 \mathrm{Db})$. The pressures in the two ventricles were recorded through the same catheter, the two cavities being entered one after the other in rapid succession and always within less than three-minute intervals. The catheter tip was placed free in the cavity. An R-C differentiation circuit was used to record the first derivative of intraventricular pressure pulses $(\mathrm{dp} / \mathrm{dt})$. These were recorded at the same sensitivity on an Electronics for Medicine DR-8 photographic recorder.

Measurements of peak pressures and peak dp/dt were made over one respiratory cycle and averaged. The peak systolic pressures are expressed as percentage ratio of one to the other, i.e. (LV systolic pressure/RV systolic pressure) $\times 100$. The peak $\mathrm{dp} / \mathrm{dt}$ of the two pressures was measured in $\mathrm{mm}$. from the base line and also expressed as percentage ratio, i.e. (dp/dt LV pressure/dp/dt RV pressure) $\times 100$.

Diagnostic angiocardiograms in both the right and left sides of the heart were performed at the end of the study.

\section{RESULTS}

The peak systolic pressures were identical in 2 patients with an associated large ventricular septal defect (VSD). In one other patient with a small 
TABLE

HAMODYNAMIC DATA AND FIRST DERIVATIVE OF RIGHT AND LEFT VENTRICULAR PRESSURE PULSES IN TRANSPOSITION OF GREAT VESSELS

\begin{tabular}{|c|c|c|c|c|c|c|c|c|c|c|c|}
\hline $\begin{array}{l}\text { Case } \\
\text { No. }\end{array}$ & Age at study & $\begin{array}{l}\text { Associated } \\
\text { defects }\end{array}$ & $\begin{array}{l}\text { LV pressure } \\
\text { (mm. Hg) }\end{array}$ & $\underset{\substack{\text { interval } \\
\text { (m.sec.) }}}{\mathbf{R}-\mathbf{R}}$ & $\begin{array}{c}\mathrm{dp} / \mathrm{dt} \\
\mathrm{LV}(\mathrm{mm} .)\end{array}$ & $\underset{(\mathrm{mm} . \mathrm{Hg})}{\text { RV pressure }}$ & $\underset{\text { interval }}{\mathbf{R}-\mathbf{R}}$ & $\begin{array}{c}\mathrm{dp} / \mathrm{dt} \\
\mathrm{RV}(\mathrm{mm} .)\end{array}$ & $\begin{array}{l}\mathrm{P} / \mathrm{S} \\
\text { flow } \\
\text { ratio }\end{array}$ & $\begin{array}{l}\text { LV syst. } \\
\text { RV syst. } \\
\text { (per cent) }\end{array}$ & $\begin{array}{l}\text { dp/dt } \\
\text { LV } \\
\text { RV }\end{array}$ \\
\hline $\begin{array}{l}1 \\
2\end{array}$ & $\begin{array}{l}1 \mathrm{yr} .2 \mathrm{mth} . \\
5 \mathrm{yr} .9 \mathrm{mth} .\end{array}$ & $\begin{array}{l}\text { ASD }(\mathbf{B}-\mathbf{H}) \\
\text { ASD }(\mathbf{B}-\mathbf{H})+\end{array}$ & $\begin{array}{l}25 / 0-5 \\
90 / 0-3\end{array}$ & $\begin{array}{l}510 \\
480\end{array}$ & $\begin{array}{r}6 \\
18\end{array}$ & $\begin{array}{l}80 / 0-5 \\
90 / 0-3\end{array}$ & $\begin{array}{l}500 \\
480\end{array}$ & $\begin{array}{l}19 \\
18\end{array}$ & $\begin{array}{l}1 \cdot 4 \\
1 \cdot 7\end{array}$ & $\begin{array}{r}32 \\
100\end{array}$ & $\begin{array}{r}32 \\
100\end{array}$ \\
\hline 3 & $6 \mathrm{mth}$. & ASD (B-H)+ & $40 / 0-8$ & 550 & 15 & $90 / 0-8$ & 500 & 26 & $2 \cdot 1$ & 45 & 57 \\
\hline $\begin{array}{l}4 \\
5 \\
6 \\
7\end{array}$ & $\begin{array}{l}8 \mathrm{yr} .11 \mathrm{mth} . \\
1 \mathrm{yr} .1 \mathrm{mth} . \\
7 \mathrm{mth} . \\
13 \mathrm{yr} .1 \mathrm{mth} .\end{array}$ & $\begin{array}{l}\text { ASD } \\
\text { ASD (B-H) } \\
\text { VSD + PS } \\
\text { ASD (B) }\end{array}$ & $\begin{array}{l}62 / 0-7 \\
40 / 0-7 \\
80 / 0-8 \\
30 / 0-8\end{array}$ & $\begin{array}{l}580 \\
600 \\
480 \\
640\end{array}$ & $\begin{array}{r}18 \\
6 \\
16 \\
12\end{array}$ & $\begin{array}{l}90 / 0-8 \\
80 / 0-8 \\
80 / 0-8 \\
80 / 0-7\end{array}$ & $\begin{array}{l}650 \\
550 \\
480 \\
640\end{array}$ & $\begin{array}{l}25 \\
12 \\
16 \\
24\end{array}$ & $\begin{array}{l}1.4 \\
3 \cdot 3 \\
0.44 \\
1.5\end{array}$ & $\begin{array}{r}69 \\
50 \\
100 \\
38\end{array}$ & $\begin{array}{r}72 \\
50 \\
100 \\
50\end{array}$ \\
\hline
\end{tabular}

ASD, atrial septal defect; VSD, ventricular septal defect; B-H, Blalock-Hanlon operation; B, Baffe's operation; PS, pulmonary stenosis.

VSD, the LV peak pressure was 45 per cent of the RV. In the remaining 4 patients with an intact interventricular septum the LV pressures were 32 to 60 per cent of the RV. Irrespective of the differences in peak systolic pressures, the enddiastolic pressures in the two ventricles were nearly equal in all cases.

In 6 patients the pulmonary/systemic flow ratio was greater than one, varying from $1 \cdot 4$ to $3 \cdot 3: 1$. In the one other with severe pulmonary stenosis, the ratio was $0 \cdot 44: 1$. The pulmonary/systemic flow ratio in patients with complete transposition represents LV/RV stroke volume ratio. Thus, the $\mathrm{LV}$ stroke volume was greater than that of the RV in all cases but one. The results in the individual cases are summarized in the accompanying Table.

The ratios of peak $\mathrm{dp} / \mathrm{dt}$ of the two ventricular
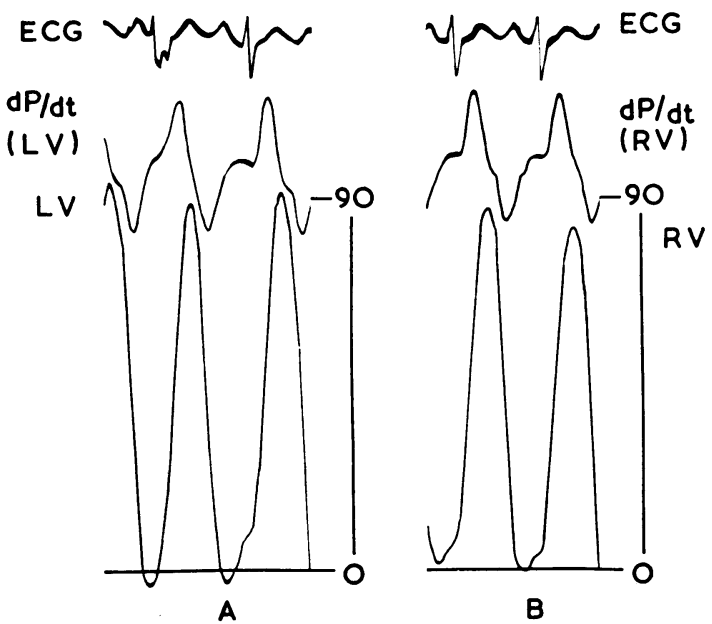

Fig. 1.-Pressures and $\mathrm{dp} / \mathrm{dt}$ in the left ventricle (A) and in the right ventricle $(B)$ in a patient with large VSD and transposition of the great vessels. pressures also varied from 32 to 100 per cent. This ratio was well correlated with the ratio of peak systolic pressures. Thus, in 2 patients with equal peak systolic pressures in the two ventricles their peak $\mathrm{dp} / \mathrm{dt}$ were also equal (Fig. 1). In the remaining 5 patients in whom LV peak systolic pressures were lower than the RV, the peak dp/dt of LV pressures were also lower (Fig. 2). A good correlation between the ratios of peak systolic pressures and the ratios of peak $\mathrm{dp} / \mathrm{dt}$ in the corresponding ventricles was noted (Fig. 3 ). Owing to the small number of patients, a statistical evaluation has not been attempted. However, it can be readily seen that the correlation is excellent in 5 and good in 2. No relation between the peak $\mathrm{dp} / \mathrm{dt}$ of the pressures and the stroke volume of either ventricle was apparent.

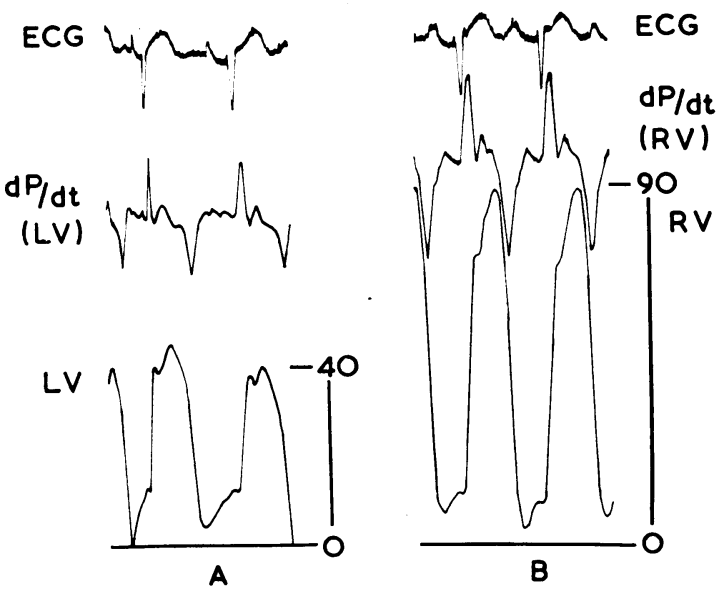

FIg. 2.-Pressures and $\mathrm{dp} / \mathrm{dt}$ in the left ventricle (A) and in the right ventricle $(B)$ in a patient with intact interventricular septum and transposition of the great vessels. 


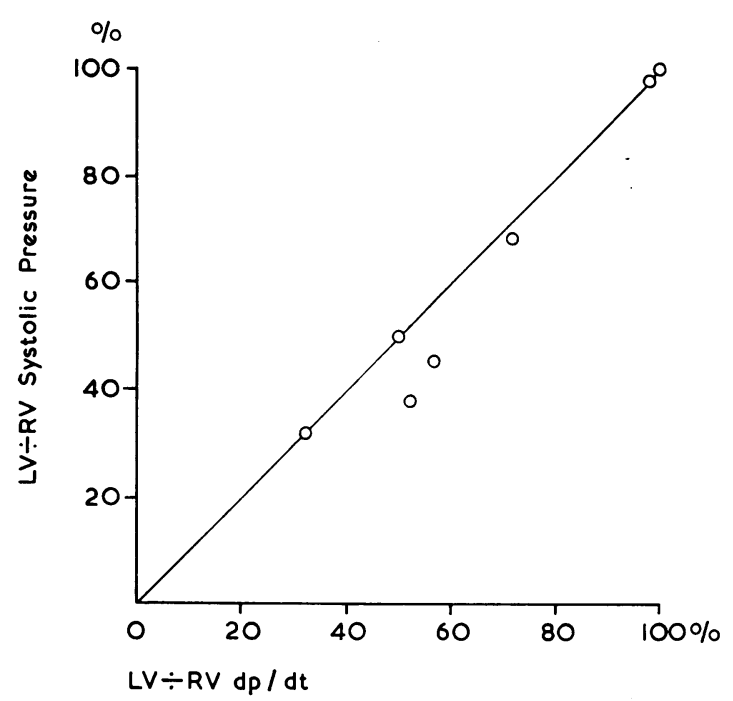

Fig. 3.-Shows a good correlation $(r=+0.984)$ between the percentage ratios of $L V / R V$ peak systolic pressures and the percentage ratios of $\mathrm{LV} / \mathrm{RV}$ peak $\mathrm{dp} / \mathrm{dt}$.

\section{DisCUSSION}

Sarnoff and Mitchell (1961) have defined an increase of myocardial contractility as "when from any given end diastolic pressure or fibre length, the ventricle produces more external stroke work and more stroke work per systolic second. Implicit in this definition is an increased rate of development of tension when contractility increases".

The factors that influence the peak $\mathrm{dp} / \mathrm{dt}$ of ventricular pressure pulses have been studied both in experimental animals and in man (Sarnoff and Mitchell, 1961; Rushmer, Smith, and Franklin, 1959; Wiggers, 1952; Reeves et al., 1960; Tolman and Young, 1961; Goldberg et al., 1953, 1960; Gleason and Braunwald, 1962). A rise in peak derivative is observed following interventions that acutely augment myocardial contractility, such as administration of isoprenaline, noradrenaline, muscular exercise, and following tachycardia. Acute changes in end-diastolic volume caused alterations in peak $\mathrm{dp} / \mathrm{dt}$, while chronic changes in volume did not.

Though catheter-tip transducers were not used and the ventricular pressures were not measured simultaneously in this study, a comparative analysis of the peak dp/dt in the two ventricles appears justified because the pressures were measured through the same catheter at less than three-minute intervals; the heart rates during the measurements were comparable, suggesting that no gross alterations in hæmodynamics had occurred in this brief period; and furthermore, the results are expressed as ratios rather than in $\mathrm{mm} . \mathrm{Hg} / \mathrm{sec}$, as only comparative assessment is attempted.

All 7 patients with complete transposition had nearly equal end-diastolic pressures in the two ventricles. This is not surprising, because all the patients had either large atrial or ventricular septal defects or both. Four patients had atrial septal defects created surgically by a Blalock-Hanlon operation, and one had had a previous Baffe's operation. In 4 patients with an intact interventricular septum and one with a small ventricular septal defect, the LV peak systolic pressure was lower than the RV; and in each of these 5 patients the pulmonary/systemic flow ratio was greater than one. Thus, at the same end-diastolic pressure the left ventricle was ejecting a larger stroke volume at a lower peak systolic pressure than the right ventricle. However, despite this, the rate of pressure development (peak dp/dt) was lower in the LV than in the $\mathrm{RV}$, suggesting that chronic volume load did not influence the rate of pressure rise in these patients. This is in agreement with the observations of Gleason and Braunwald (1962), who reported that the peak LV dp/dt was not different from normal in patients with mitral and aortic incompetence.

The ratios of peak $\mathrm{dp} / \mathrm{dt}$ in the two ventricles were in fair agreement with the ratios of peak systolic pressures. Thus, in cases of complete transposition where the normal pressure relationship of the ventricles is reversed, the peak rate of pressure development is also reversed. As the inner architecture and shape of the ventricular cavities were identified by angiocardiography as being grossly normal, it appears that the peak $\mathrm{dp} / \mathrm{dt}$ is not related to the architectural identity of the ventricle, but rather to the peak systolic pressure it develops.

Acute changes in peak systolic pressure, however, bear no constant relation to changes in peak $\mathrm{dp} / \mathrm{dt}$. Gleason and Braunwald (1962) showed that following administration of isoprenaline, the peak $\mathrm{dp} / \mathrm{dt}$ in the LV increases while the systolic pressure is unchanged. Conversely, following the administration of methoxamine, a rise in peak systolic pressure may be accompanied by a decrease in peak $\mathrm{dp} /$ dt. As this is well established, the correlation noted in the present study is probably related to the relative thickness of the two ventricular walls. The right ventricle in complete transposition of great vessels chronically faces a higher pressure load than the left, and would be expected to develop a greater wall thickness as a consequence (Sandler, Dodge, and Hay, 1961).

The results of the present study suggest that the higher rate of development of tension in the left ventricle in a normal heart is probably related to thickness of the wall rather than to the intrinsic 
architecture of the muscle fibres. Each ventricle is capable of modifying this function according to the chronic resistance load against which it is made to pump.

\section{SUMMARY}

A comparison of the first derivative of the intraventricular pressures has been made in 7 patients with complete transposition of the great vessels.

Where the peak systolic pressure relationships in the right and left ventricles were the reverse of those in normal hearts, the ratios of peak dp/dt were also reversed, the two ratios correlating well.

Thus, the peak rate of development of tension in either ventricle is related to the function of the ventricle in terms of pressure load, and is not predetermined by its embryological or anatomical identity.

It is suggested that the peak $\mathrm{dp} / \mathrm{dt}$ is dependent on the myocardial thickness and not on chronic volume load or the architecture of the ventricular walls.

We wish to thank Dr. J. D. Keith for his help and encouragement, Dr. R. M. Shaher for his active cooperation, Mr. Lee Tripp for technical help, and Miss Eleanor Wilson for secretarial assistance.

\section{REFERENCES}

Gleason, W. L., and Braunwald, E. (1962). Studies on the first derivative of the ventricular pressure pulse in man. 7. clin. Invest., 41, 80.

Goldberg, L. I., Bloodwell, R. D., Braunwald, E., and Morrow, A. G. (1960). The direct effects of norepinephrine, epinephrine, and methoxamine on myocardial contractile force in man. Circulation, 22, 1125.

—, Cotten, M. deV., Darby, T. D., and Howell, E.V. (1953). Comparative heart contractile force effects of equipressor doses of several sympathomimetic amines. f. Pharmacol. exp. Ther., 108, 177.

Reeves, T. J., Hefner, L. L., Jones, W. B., Coghlan, C., Prieto, G., and Carroll, J. (1960). The hemodynamic determinants of the rate of change in pressure in the left ventricle during isometric contraction. Amer. Heart f., 60, 745.

Rushmer, R. F. (1961). Cardiovascular Dynamics, 2nd ed, pp. 45 and 46. Saunders, Philadelphia.

-, Smith, O., and Franklin, D. (1959). Mechanisms of cardiac control in exercise. Circulat. Res., 7, 602.

Sandler, H., Dodge, H., and Hay, R. (1961). Left ventricular tension and stress in man. Clin. Res., 9, 145.

Sarnoff, S. J., and Mitchell, J. H. (1961). The regulation of the performance of the heart. Amer. F. Med., 30, 747.

Tolman, R. A., and Young, P. G. (1961). Slope changes of ventricular pressure curves compared with ventricular function curves. Fed. Proc., $20,124$.

Wiggers, C. J. (1952). Dynamics of ventricular contraction under abnormal conditions. Circulation, 5, 321. 